\title{
Alterations in mitogenic and steroidogenic activities in rat testicular interstitial fluid after administration of ethane dimethane sulphonate
}

\author{
A. E. Drummond, G. P. Risbridger, P. C. O'Leary and D. M. de Kretser \\ Department of Anatomy, Monash University, Clayton, Victoria 3168, Australia
}

\begin{abstract}
Summary. A single dose of EDS was given to mature male rats and interstitial fluid (IF) was collected to determine the potency of mitogenic and steroidogenic activities therein. The potency of the factor stimulating testosterone secretion in vitro by Percoll-purified Leydig cells was significantly elevated 2 weeks after EDS, whilst the potency of mitogenic activities (stimulation of DNA synthesis by BALB/c 3 T3 cells) was not elevated until 4 weeks after EDS treatment.

This study suggests that two separate factors, one with mitogenic and the other steroidogenic activity, may be involved in the response of Leydig cells after EDS administration. The mitogenic factor may play a role in Leydig cell regeneration whereas the testosterone-stimulating factor may be involved in testicular testosterone homeostasis.
\end{abstract}

Keywords: mitogenesis; interstitial fluid; steroidogenesis; Leydig cell

\section{Introduction}

The influence of the seminiferous tubule on Leydig cell function is well documented by a series of articles detailing the effects of disrupted spermatogenesis (via efferent duct ligation, hydroxyurea treatment, X-irradiation, experimental cryptorchidism or vitamin A deficiency) on the intertubular tissue (Rich \& de Kretser, 1977; Aoki \& Fawcett, 1978; Rich et al., 1979; Kerr et al., 1979; Risbridger et al., 1981 a, b, c). These studies report the presence of hypertrophic Leydig cells with diminished capacity for testosterone secretion in vivo, and increased responsiveness to hCG stimulation in vitro. In rats with unilateral or focal spermatogenic damage, the Leydig cell changes were limited to those in proximity to the damaged tubules, supporting a paracrine mechanism of regulating Leydig cell function (Aoki \& Fawcett, 1978). Evidence exists that such paracrine mechanisms may operate through a testosterone-stimulating factor and a mitogenic factor, both previously detected in interstitial fluid (Sharpe \& Cooper, 1984; Risbridger et al., 1986, 1987).

It is well established that the cytotoxin, ethane dimethane sulphonate (EDS), selectively destroys testicular Leydig cells, removing them from the intertubular tissue for a transient period, with Leydig cell regeneration beginning 2-4 weeks after treatment (Morris \& McCluckie, 1979; Jackson \& Jackson, 1984; Kerr et al., 1985; Jackson et al., 1986; Morris et al., 1986). The EDS-treated animal is therefore useful for study of the activities of factors in testicular interstitial fluid, which may be involved in the testicular response to this cytotoxin.

O'Leary et al. (1986) have demonstrated that Leydig cell regeneration in the damaged cryptorchid testis was faster than in the contralateral scrotal testis. The mitogenic factor found in interstitial fluid may therefore be responsible for the rapid regeneration and the testosterone-stimulating factor may be involved in testicular steroid homeostasis (Sharpe et al., 1986b; Risbridger et al., 1986). This study assesses the changes in potency of these substances in interstitial fluid after EDS administration. 


\section{Materials and Methods}

Animal treatment and interstitial fluid (IF) collection. Adult male Sprague-Dawley rats were obtained from Central Animal Services, Monash University. EDS dissolved in dimethyl sulphoxide (DMSO) (British Drug Houses Poole, U.K.), was administered intraperitoneally to groups of rats, as a single dose of $75 \mathrm{mg} / \mathrm{kg}$, whilst control groups received injections of the vehicle, DMSO. Rats from each group $(\mathrm{N}=10)$ were killed at time 0,4 days, and 1,2 and 4 weeks after EDS treatment. The testes were removed and IF was allowed to drain from an incision in the tunica albuginea, into a test tube, for $16 \mathrm{~h}$ at $4^{\circ} \mathrm{C}$ (Sharpe \& Cooper, 1983). The volume of IF collected was recorded after centrifugation and the concentration of testosterone in a sample was measured. The results were analysed by Student's $t$ tests. IF was stored at $-20^{\circ} \mathrm{C}$ until required for assay.

Bioassay of steroidogenic activity in testicular IF. Single-point and dose-dependent stimulations of testosterone production by Percoll-purified Leydig cells in vitro were determined as described by Risbridger et al. (1986, 1987). Briefly, purified collagenase-dispersed interstitial cells $\left(5 \times 10^{4}\right.$ cells/well) from adult male rats were incubated with test fluids for $20 \mathrm{~h}$ at $32^{\circ} \mathrm{C}$. In the single-point assay experiment, IF samples $(n=7)$ were assayed at a single dose level, with the results analysed using Student's $t$ tests. In other experiments a dose-response was obtained utilizing pools of IF, formed by combining equal volumes of IF from individual animals in a group. These samples were then assayed in a single experiment utilizing the same preparation of Leydig cells. The potencies of IF collected from EDS-treated testes were determined relative to control IF samples, using parallel-line bioassay statistics (Finney, 1964). The activity of control IF was defined as $1 \mathrm{unit} / \mathrm{ml}$.

Bioassay of mitogenic activity in testicular IF. A method similar to that described by Feig et al. (1980) was utilized to measure mitogenic activity in the collected samples. Briefly, mouse embryo fibroblasts, kindly supplied by Dr C. Lloyd (Ludwig Institute, Melbourne, Australia) were maintained at $37^{\circ} \mathrm{C}$, under $5 \% \mathrm{CO}_{2}$ in Dulbecco's modified Eagle's medium (DMEM) (Flow Laboratories, McLean, VA, U.S.A.) supplemented with $10 \%$ fetal calf serum (FCS) (Gibco Chagrin Falls, OH, U.S.A.), glucose (4.5 g/l), penicillin (50 units/ml) and streptomycin sulphate $(50 \mathrm{~g} / \mathrm{ml}: \mathrm{CSL}$, Melbourne, Australia).

Stock cultures of BALB/c, 3T3 cells were trypsinized and suspended in DMEM and $10 \%$ FCS, at a concentration of $5 \times 10^{4} \mathrm{cells} / \mathrm{ml}$. Samples of $200 \mu \mathrm{l}$ were placed in 96-well culture plates (Linbro, Flow Laboratories) and incubated without a change of medium until the cells became confluent and quiescent, approximately 4 days. The confluent cell monolayers were incubated in DMEM $+0.5 \%$ FCS overnight, before the addition of IF samples. Aliquants of pools of IF were incubated at multiple dose levels, in replicates of 3 or 4 , for $20 \mathrm{~h}$ at $37^{\circ} \mathrm{C}$, under $5 \% \mathrm{CO}_{2}$, with all test fluids being assayed in a single experiment. $\left[{ }^{3} \mathrm{H}\right]$ Thymidine (sp. act. $6.7 \mathrm{Ci} / \mathrm{mmol}$ : NEN, Boston, MA, U.S.A.), at a concentration of $4 \mu \mathrm{Ci} / \mathrm{ml}$ was then added to the cells and incubated for a further $2 \mathrm{~h}$. Immediately after the final incubation period the cells were fixed in methanol, washed with water, extracted with $5 \%$ TCA and lysed with $0.3 \mathrm{M}-\mathrm{NaOH}$. The incorporation of tracer into DNA was determined by liquid scintillation counting (Packard).

The dose-respone curves of IF were assessed for linearity and parallelism, with the potencies of test fluids determined relative to control IF using parallel-line bioassay statistics (Finney, 1964). The activity of control IF was defined as 1 unit/ml.

Radioimmunoassay for testosterone in IF and serum. Testosterone in IF was measured directly whilst serum samples were extracted with ether by a method similar to that described by Corker \& Davidson (1978). $\left[{ }^{3} \mathrm{H}\right] \mathrm{Testosterone}$ was utilized as a ligand with antiserum provided by Dr R. I. Cox (CSIRO, Prospect, NSW, Australia), which showed $98 \%$ cross-reactivity with $5 a$-dihydrotestosterone. The inter-and intra-assay coefficients of variation were 7.9 and $8.0 \%$ respectively and the sensitivity of the assay was $6 \mathrm{pg} / \mathrm{tube}$.

\section{Results}

\section{Volumes and testosterone concentrations of IF}

The volume of IF collected 4 days and 1 week after EDS treatment was severely reduced $(P<0.001)$ compared to controls (Table 1$)$ and remained low for 2 weeks after $\operatorname{EDS}(P<0.01)$, returning to control levels thereafter.

The concentration of testosterone in IF 4 days and 1 week after EDS treatment declined significantly $(P<0.001)$ to almost non-detectable levels (Table 1). Values rose 2 weeks after treatment, but remained significantly lower $(P<0.001)$ than normal, returning to control levels 4 weeks after EDS treatment (Table 1). Serum testosterone values were significantly $(P<0.001)$ lower than control values at 4 days, 1 and 2 weeks after EDS treatment (Table 1).

\section{Stimulatory steroidogenic activity in IF}

Testicular IF stimulated testosterone production in vitro. IF assayed at a single dose level was significantly more potent $(P<0.01)$ compared to controls (Fig. 1) at 2 weeks after EDS treatment, 
Table 1. The effect of EDS treatment on IF volumes, IF testosterone concentrations and serum testosterone concentrations in rats

\begin{tabular}{lccc}
\hline $\begin{array}{l}\text { Time after } \\
\text { EDS }\end{array}$ & IF vol. $(\mu \mathrm{l})$ & $\begin{array}{c}\text { IF testosterone } \\
\text { conc. }(\mathrm{ng} / \mathrm{ml}) \dagger\end{array}$ & $\begin{array}{c}\text { Serum testosterone } \\
\text { conc. }(\mathrm{ng} / \mathrm{ml})\end{array}$ \\
\hline 0 & $140 \pm 9 \cdot 8$ & $214 \pm 27$ & $3 \cdot 49 \pm 0 \cdot 6$ \\
4 days & $41 \pm 4 \cdot 9^{*}$ & $\mathrm{ND}$ & $0 \cdot 54 \pm 0 \cdot 03^{*}$ \\
l week & $34 \pm 3 \cdot 2^{*}$ & $6 \cdot 3 \pm 1^{*}$ & $0 \cdot 34 \pm 0 \cdot 01^{*}$ \\
2 weeks & $102 \pm 18^{* *}$ & $50 \pm 6^{*}$ & $0 \cdot 91 \pm 0 \cdot 18^{*}$ \\
4 weeks & $172 \pm 28$ & $173 \pm 23$ & $3 \cdot 62 \pm 0 \cdot 5$ \\
\hline
\end{tabular}

Values are mean \pm s.e.m. for 10 rats per group.

${ }^{*} P<0.001,{ }^{* *} P<0.01$ compared to controls.

†Samples assayed after dilution; limit of detection of the assay was $5 \cdot 04 \mathrm{ng} / \mathrm{ml}$, concentrations below this are considered non-detectable (ND).

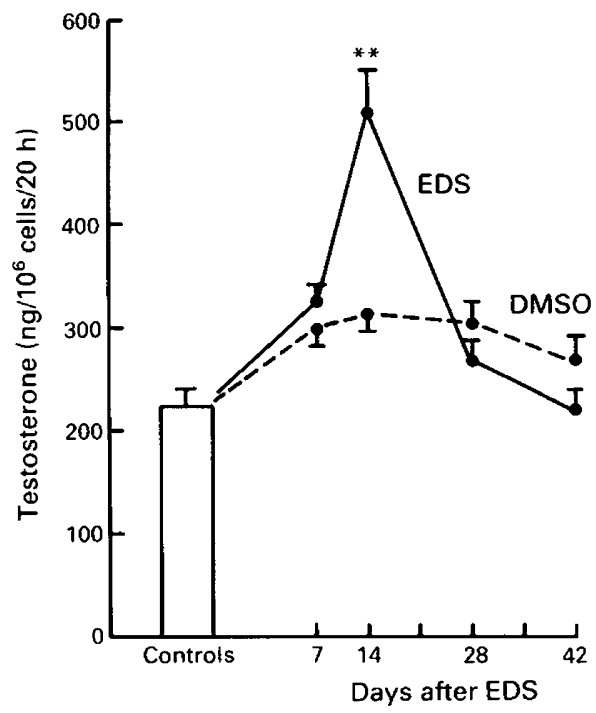

Fig. 1. Testosterone production by purified Leydig cells in vitro stimulated by IF, collected after treatment of rats with EDS or the vehicle, DMSO. Each point is the mean \pm s.e.m. $(n=7)$. ${ }^{* *} P<0.01$ compared to control value.

but at no other time. Dose-response curves of pooled IF samples, collected from a second group of treated animals, caused linear and parallel increases in testosterone production with the assay having an index of precision of $\lambda=0.05$ (Fig. 2). These results consolidate single-point data in that the potency of IF was significantly $(P<0.05)$ elevated above controls at 2 weeks after EDS, returning to control levels by 4 weeks after EDS treatment. Potency estimates of steroidogenic stimulatory factors in IF were 1.00, 1.52 (confidence limits 1.34-1.77) and 0.97 (confidence limits $0 \cdot 81-1 \cdot 16)$ for control, 2 and 4 week IF pools respectively.

\section{Stimulatory mitogenic activity in IF}

Testicular IF caused dose-dependent increases in the incorporation of [methyl- ${ }^{3} \mathrm{H}$ ]thymidine into BALB/c 3T3 cells (Fig. 3). The dose-response curves were linear and parallel, with the assay 


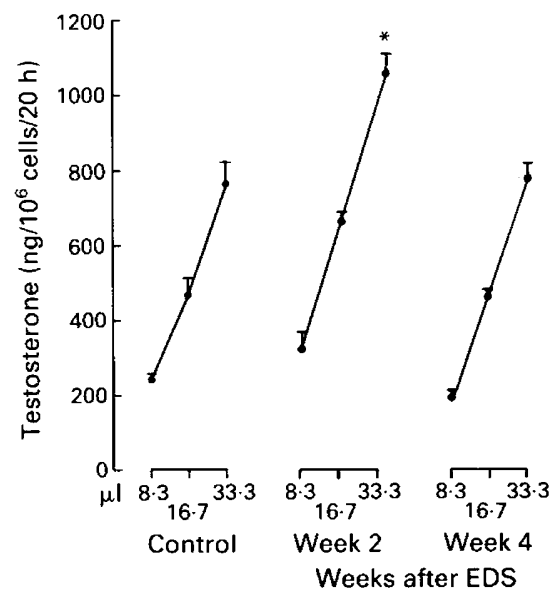

Fig. 2. Dose-dependent stimulations of testosterone production by Leydig cells in vitro, induced by IF, collected after EDS treatment of rats. Pools of IF $(n=10)$ were assayed at multiple dose levels in a single experiment. Each point represents the mean \pm s.e.m. $(n=4)$. The curves were linear and parallel (bioassay statistics). ${ }^{*} P<0.05$ compared to control value.

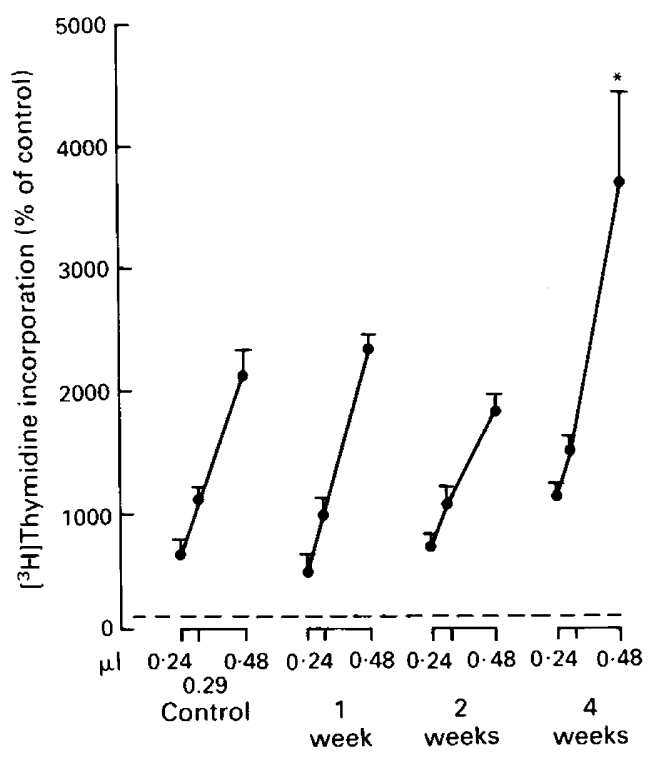

Time after EDS treatment

Fig. 3. Pooled IF collected from EDS-treated animals, at time points over a period of 4 weeks stimulated dose-dependent increases in tracer incorporation into BALB/c $3 T 3$ cells. Each point is the mean \pm s.e.m. $(n=10)$ illustrated as a percentage of control, where $100 \%$ incorporation (broken line) represents the tracer incorporated by unstimulated control cells. The curves were linear and parallel. ${ }^{*} P<0.05$ compared to control value. 
Table 2. The effect of EDS treatment of rats on the potency of mitogenic factors in IF

\begin{tabular}{|c|c|c|}
\hline \multirow{2}{*}{$\begin{array}{l}\text { Time after } \\
\text { EDS }\end{array}$} & \multicolumn{2}{|c|}{ Mitogenic activity in IF } \\
\hline & Potency & $95 \%$ Limits \\
\hline 0 & $\begin{array}{c}1.0 \\
\text { (by definition) }\end{array}$ & \\
\hline 1 week & 1.016 & $0.77-1.33$ \\
\hline 2 weeks & 1.001 & $0.77-1.28$ \\
\hline 4 weeks & $1.437^{*}$ & $1 \cdot 12-1.96$ \\
\hline
\end{tabular}

having an index of precision of $\lambda=0 \cdot 10$. At 4 weeks after EDS, and at no other time, the potency of mitogenic factors in collected IF was significantly greater $(P<0.05)$ than in control IF (Table 2$)$.

\section{Discussion}

This study demonstrates that mitogenic and stimulatory steroidogenic activities in testicular IF are altered during Leydig cell destruction and regeneration after EDS treatment. The results suggest that these two activities are likely to be due to separate substances since their activities show different patterns in the experimental regimen used in this study.

The presence of growth factors in the testis has been established utilizing 3T3 cell bioassays, exclusively (Feig et al., 1980) or in part (Holmes et al., 1986). It would be preferable to assess mitogenic potency using Leydig cell or Leydig cell precursor cultures. However, no known method of maintaining mature rat Leydig cells in long-term culture is available and so the 3T3 cell culture assay established by Feig et al. (1980) was used as a viable mitogenic assay system.

Basic fibroblast growth factor (FGF) has been purified from testes of cattle (Ueno et al., 1987). Whilst mitogenic activity contributed by FGF may play a role in regulating testicular function, the activity in our preparation lacks important characteristics which classify FGF-like proteins (A. E. Drummond, G. P. Risbridger \& D. M. de Kretser, unpublished observations) and therefore appears distinct from FGF.

Mitogenic activity has been described also in Sertoli cell culture media, and Holmes et al. (1986) postulated that this substance(s) played a role in spermatogenesis and/or regulated Leydig cell numbers. The polypeptide of Holmes et al. (1986) was distinct from a polypeptide isolated and purified from mouse Sertoli cells by Feig et al. (1980) which was believed to stimulate spermatogonial mitosis. Whether the mitogenic activity we have detected in IF is the same as either of these two polypeptides remains to be determined. It is possible that the presence of mitogenic activity in IF results from the basal secretion of activity by the Sertoli cells and that the destruction of Leydig cells and subsequent disruption of spermatogenesis combined with an alteration in Sertoli cell function, leads to an altered secretory pattern of this factor. The time taken to effect this change may account for the delay in elevation of mitogenic activity. Results from EDS/unilaterally cryptorchid animal experiments (A. E. Drummond, G. P. Risbridger \& D. M. de Kretser, unpublished observations) suggest that the production of this mitogenic activity within the testes is locally controlled.

Steroidogenic stimulatory activity has previously been detected in IF (Sharpe \& Cooper, 1984; Risbridger et al., 1986). The utilization of dose-response curves and hence parallel-line bioassay 
statistics has consolidated the data available from single-point assay experiments and has allowed potency estimates to be made. Studies of other models of testicular damage (e.g. cryptorchidism: Risbridger et al., 1987; Sharpe et al., 1986a) have demonstrated that concentrations of this stimulatory factor in IF are elevated whenever spermatogenesis is disrupted and Sertoli cell function is altered (O'Leary et al., 1986), as shown by decreased production of androgen binding protein and seminiferous tubule fluid. The potency of stimulatory steroidogenic factors in IF is significantly elevated above controls at 2 weeks after EDS, a time when testosterone concentrations in serum and IF are grossly decreased and coincident with maximum disruption to the seminiferous epithelium (Kerr et al., 1985; Bartlett $e$ t al., 1986). These results are consistent with data reported by Sharpe et al. (1986b) which also demonstrated elevated amounts of bioactivity in IF 2 weeks after EDS injection. A concentrating mechanism, effected through reduced IF volumes, is unlikely to be entirely responsible for the increased potency of this factor. IF volumes are markedly reduced 1 week after EDS injection, yet a subsequent 3-fold increase in these levels 2 weeks after EDS injection coincides with the increased potency of steroidogenic factors in IF. Steroidogenic stimulatory factors in IF return to control levels with the re-establishment of normal testosterone concentrations in the testis. We were unable to confirm reports of elevated bioactivity up to 10 weeks after EDS treatment (Sharpe et al., 1986a) in single-point or dose-response studies of IF bioactivity.

There is general agreement (Kerr et al., 1985; Jackson et al., 1986) that the absolute volume of Leydig cells in the interstitium, determined by morphometry, declines to undetectable levels after EDS injection (Jackson et al., 1986). Both studies showed that the redifferentiation of Leydig cells occurred from Day 14 to Day 28 after EDS treatment. Despite lower than normal absolute volume of Leydig cells, testosterone concentrations returned to control levels by 4 weeks after EDS injection. This suggests that there may be other factors contributing to total testosterone production. For example, Leydig cell precursor cells may be capable of synthesizing testosterone, or the few Leydig cells present at the beginning of the regeneration phase may have an increased capacity for testosterone production in response to endogenous $\mathrm{LH}$.

Further investigation is required to isolate the source(s) and to identify these local factors. Clearly destruction of Leydig cells and the associated disruption of spermatogenesis and altered Sertoli cell function, the result of EDS treatment, changes the pattern of activities of these factors differentially, indicating that stimulatory steroidogenic and mitogenic activities are due to different substances in IF.

We thank Dr C Lloyd for advice and discussion, and Ms J. Muir and Mrs M. Richards for excellent technical assistance. This study was supported by a grant from the NH \& MRC of Australia.

\section{References}

Aoki, A. \& Fawcett, D.W. (1978) Is there a local feedback from the seminiferous tubules affecting activity of the Leydig cells? Biol. Reprod. 19, 144-158.

Bartlett, J.M.S., Kerr, J.B. \& Sharpe, R.M. (1986) The effect of selective destruction and regeneration of rat Leydig cells on the intratesticular distribution of testosterone and morphology of the seminiferous epithelium. J. Androl. 7, 240-253.

Corker, C.S. \& Davidson, D.W. (1978) A radioimmunoassay for testosterone in various biological fluids without chromatography. J. Steroid Biochem. 9, 373-374.

Feig, L.A., Bellve, A.R., Horbach-Erickson, N. \& Klagsbrun, M. (1980) Sertoli cells contain a mitogenic polypeptide. Proc. natn. Acad. Sci. U.S.A. 77, 4774-4778.
Finney, D.J. (1964) Statistical Methods of Biological Assay, 3rd edn. Griffin \& Co., London.

Holmes, S.D., Spotts, G. \& Smith, R.G. (1986) Rat Sertoli cells secrete a growth factor that blocks epidermal growth factor (EGF) binding to its receptor. J. biol. Chem. 261, 4076-4080.

Jackson, A.E., O'Leary, P.C., Ayers, M. \& de Kretser, D.M. (1986) The effects of ethylene dimethane sulphonate (EDS) on rat Leydig cells: evidence to support a connective tissue origin of Leydig cells. Biol. Reprod. 35, 425- 437.

Jackson, C.M. \& Jackson, H. (1984) Comparative protective actions of gonadotrophins and testosterone against the antispermatogenic action of ethane dimethane sulphonate. J. Reprod. Fert. 71, 393-401.

Kerr, J.B., Rich, K.A. \& de Kretser, D.M. (1979) 
Alterations of the fine structure and androgen secretion of the interstitial cells in the experimentally cryptorchid rat testis. Biol. Reprod. 20, 409-422.

Kerr, J.B., Donachie, K. \& Rommerts, F.F.G. (1985) Selective destruction and regeneration of rat Leydig cells in vivo. Cell Tiss. Res. 242, 145-156.

Morris, I.D. \& McCluckie, J.A. (1979) Temporal changes in serum androgen after temporary impairment of Leydig cell function by ethane-1,2-dimethane sulphonate. J. Steroid Biochem. 10, 467-469.

Morris, I.D., Phillips, D.M. \& Bardin, C.W. (1986) Ethylene dimethanesulfonate destroys Leydig cells in the rat testis. Endocrinology 118, 709-719.

O'Leary, P.C., Jackson, A.E., Averill, S. \& de Kretser, D.M. (1986) Effects of EDS on bilaterally cryptorchid rat testes. Molec. cell. Endocr. 45, 183-190.

Rich, K.A. \& de Kretser, D.M. (1977) Effect of differing degrees of destruction of the rat seminiferous epithelium on levels of serum FSH and androgen binding protein. Endocrinology 101, 959-968.

Rich, K.A., Kerr, J.B. \& de Kretser, D.M. (1979) Evidence for Leydig cell dysfunction in rats with seminiferous tubule damage. Molec. cell. Endocr. 13, 123-135.

Risbridger, G.P., Kerr, J.B. \& de Kretser, D.M. (1981a) Evaluation of Leydig cell function and gonadotrophin binding in unilateral and bilateral cryptorchid: evidence for local control of Leydig cell function by the seminiferous tubule. Biol. Reprod. 24, 534-540.

Risbridger, G.P., Kerr, J.B., Peake, R.A. \& de Kretser, D.M. (1981b) An assessment of Leydig cell function after bilateral or unilateral efferent duct ligation: further evidence for local control of Leydig cell function. Endocrinology 109, 1234-1241.
Risbridger, G.P., Kerr, J.B., Peake, R.A., Rich, K.A. \& de Kretser, D.M. (1981c) Temporal changes in rat Leydig cell function after the induction of bilateral cryptorchidism. J. Reprod. Fert. 63, 415-423.

Risbridger, G.P., Kerr, J.B. \& de Kretser, D.M. (1986) Influence of the cryptorchid testis on the regeneration of rat Leydig cells after the administration of ethane dimethane sulphonate. J. Endocr. 112, 197-204.

Risbridger, G.P., Drummond, A.E. \& de Kretser, D.M. (1987) The effect of cryptorchidism on steroidogenic and mitogenic activities in rat testicular interstitial fluid. J. Reprod. Fert. 81, 617-624.

Sharpe, R.M. \& Cooper, I. (1983) Testicular interstitial fluid as a monitor for changes in the intratesticular environment in the rat. J. Reprod. Fert. 69, 125-135.

Sharpe, R.M. \& Cooper, I. (1984) Intratesticular secretion factor(s) with major stimulatory effects on Leydig cell testosterone secretion in vitro. Molec. cell. Endocr. 37, 159-168.

Sharpe, R.M., Kerr, J.B., Cooper, I. \& Bartlett, J.M.S. (1986a) Intratesticular factors and testosterone secretion: the effect of ethane dimethane sulphonate (EDS) and the induction of seminiferous tubule damage. Int. J. Androl. 9, 285-298.

Sharpe, R.M., Kerr, J.B., Fraser, H.M. \& Bartlett, J.M.S. (1986b) Intratesticular factors and testosterone secretion: effects of treatments that alter the level of testosterone within the testis. J. Androl. 7, 180-189.

Ueno, N., Baird, A., Esch, F., Ling, N. \& Guillemin, R. (1987) Isolation and partial characterisation of basic fibroblast growth factor from bovine testis. Molec. cell. Endocr. 40, 189-194.

Received 9 July 1987 